\title{
A INFLUÊNCIA DO CONTEXTO HISTÓRICO NA CONFIGURAÇÃO FORMAL E ASPECTOS SIMBÓLICOS DOS PRODUTOS
}

Frederico Mendes Teixeira, Mestre

Universidade do Estado de Minas Gerais, Unidade Ubá

frederico.mendes@uemguba.edu.br

Juliana Martins de Souza

Universidade do Estado de Minas Gerais, Unidade Ubá

julianadesigndeproduto@gmail.com

Resumo: O conhecimento dos princípios da percepção é importante ferramenta para designers. Através da compreensão do usuário e suas necessidades, o designer estabelece critérios assertivos de desenvolvimento do projeto. $\mathrm{O}$ aspecto formal do produto transmite significados que refletem conceitos complexos como valor e gosto, variáveis de acordo com o contexto de inserção. A comunicação entre o produto e o usuário é feita, inicialmente, através do sentido da visão. 0 usuário observa forma, cores, texturas, acabamentos e verifica se aquele produto é atraente ou não. Após este contato e com alguma experiência com o objeto, faz associações semânticas e se apropria pelo produto. Para que isto aconteça, deve haver reconhecimento dos benefícios intangíveis do produto e inserção do mesmo no meio cultural, social, político e econômico. Ou seja, o produto é atraente para o usuário que, por sua vez, está inserido em determinado contexto histórico, e busca satisfazer anseios através do consumo de bens que sejam reflexo de si, de sua personalidade e estilo de vida. Ao projetar, o designer deve considerar funções de uso e funções de estima do produto. Considerando-se que o primeiro item refere-se a aspectos instrumentais, este trabalho tem como foco o segundo, que se refere aos aspectos subjetivos do design. Neste sentido, a pergunta de partida que conduziu este trabalho é "Como o contexto histórico, social e político no qual um produto está inserido influencia em sua configuração formal e simbólica?". Esta questão explorou dois conceitos principais que direcionam a pesquisa: 1) o contexto histórico, social e político do usuário e 2) a configuração do objeto em sua forma e seu significado. Buscamos compreender os fundamentos da percepção, assim como, aprofundar nas questões simbólicas do produto. $\mathrm{O}$ levantamento bibliográfico proporcionou a verificação de que o contexto histórico de uma época influencia na configuração dos objetos, uma vez que o produto é resultado da disponibilidade de tecnologia e processos industriais. O modo como uma sociedade se organiza economicamente influencia no tipo de objeto produzido e, consequentemente, no modo de operação da indústria. O contexto econômico estável dos anos 1950 no 
Brasil impulsionou a industrialização e trouxe à tona uma massificação de produtos. No que diz respeito ao aspecto formal e simbólico dos produtos, não foi possível verificar através dos materiais e métodos propostos uma relação direta entre os atributos de uma era à forma e significado dos objetos. Os entrevistados fizeram atribuições distintas aos produtos, de acordo com suas próprias interpretações, alguns produtos foram considerados mais "estáveis", "leves" ou "revolucionários", porém não houve relação entre as cadeiras e as eras. Concluiu-se que, o usuário faz livre interpretação do objeto, de acordo com seu próprio contexto, e não de acordo com o contexto do objeto. A percepção é um fenômeno universal no que tange ao uso dos sentidos. No entanto, a atribuição de significados de um produto faz parte do repertório do interpretante.

Palavras-chave: Design, Percepção, Teoria do Design 